January 2013

\title{
Pharmacological agents for preventing morbidity associated with the haemodynamic response to tracheal intubation
}

Fauzia A. Khan

Aga Khan University, fauzia.khan@aku.edu

Hameed Ullah

Aga Khan University, hameed.ullah@aku.edu

Follow this and additional works at: https://ecommons.aku.edu/pakistan_fhs_mc_anaesth

Part of the Anesthesia and Analgesia Commons, and the Anesthesiology Commons

\section{Recommended Citation}

Khan, F. A., Ullah, H. (2013). Pharmacological agents for preventing morbidity associated with the haemodynamic response to tracheal intubation. The Cochrane Database of Systematic Reviews (7).

Available at: https://ecommons.aku.edu/pakistan_fhs_mc_anaesth/284 


\section{Physical Manipulation of Larynx as a Technique for Insertion of Nasogastric Tube}

Sir,

Nasogastric (NG) tube insertion is often a difficult task in patients who are anesthesized and have endotracheal tubes in situ. The failure rate of insertion in the first attempt is reported to be as high as $50 \%$ in neutral position of the head. 1 The most common sites of impaction of orogastric and NG tubes are the pyriform sinuses and arytenoid cartilages. ${ }^{2}$ Frequent unsuccessful attempts may lead to hemodynamic instability (tachycardia, hypertension) and nasal mucosal bleed.

Different methods have been suggested to reduce the number of unsuccessful attempts. These include the use of slit endotracheal tube, neck flexion with lateral neck pressure, use of glidescope, use of guidewire or angiography catheter. ${ }^{3}$ Physical lifting of the larynx off the esophagus (reverse Sellick's maneuver) has been investigated in one study only. 4

We report a case of a 40-year male Chinese patient where we used this method successfully. The Chinese patients have larger superoposterior airway space, a larger nasopharynx and oropharynx cross-sectional area with a smaller tongue thickness. ${ }^{5}$ These features distinguish the Chinese population from other Asian races.

Our patient weighed $75 \mathrm{~kg}$ with a body mass index (BMI) of $27.5 \mathrm{~kg} / \mathrm{m}^{2}$ and was scheduled for laparoscopic cholecystectomy for cholelithiasis. The laboratory parameters were normal except for mild hyponatremia with sodium of $133 \mathrm{meq} / \mathrm{l}$.

After application of standard monitoring, general anaesthesia was initiated. Gastric decompression was required by the surgeons; therefore a NG tube of $16 \mathrm{Fr}$ was attempted orally after lubricating the distal end of the tube with a water soluble gel. Two unsuccessful attempts were made, but the NG tube failed to pass from the oropharynx into the esophagus. A third attempt was made by physically lifting the larynx off the esophagus by holding it on both sides with the help of thumb and index finger (Figure 1). This simple physical maneuver resulted in the NG tube passing easily from the oropharynx into the stomach. NG tube placement was confirmed by auscultation at the epigastrium.
This simple maneuver reduced the number of unsuccessful attempts and we recommend further research on it.

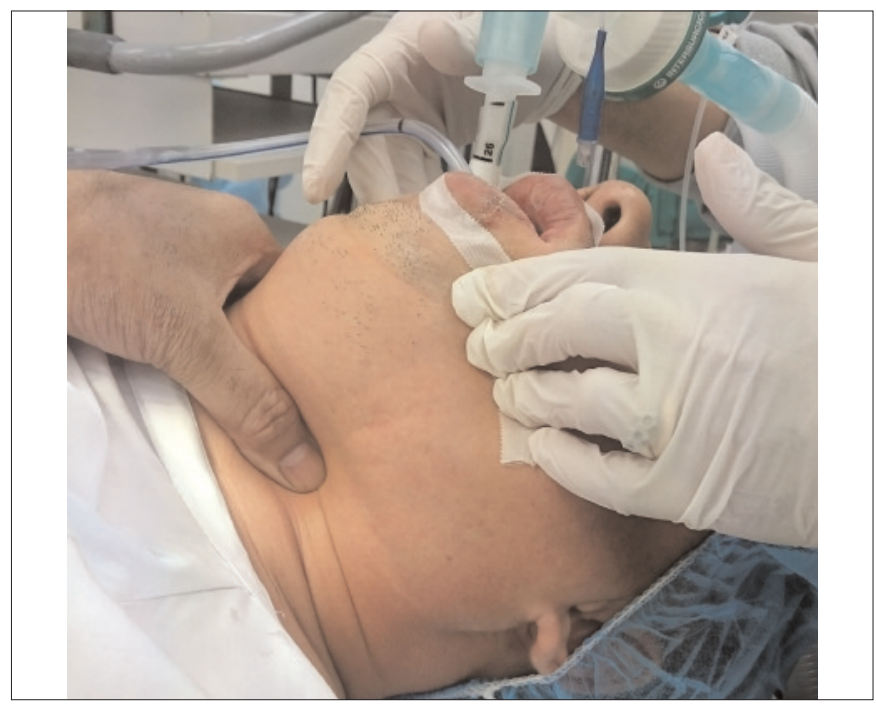

Figure 1: Physically lifting the larynx off the esophagus by holding it on both sides with the help of thumb and index finger.

\section{REFERENCES}

1. Mahajan R, Gupta R. Another method to assist nasogastric tube insertion. Can J Anesth 2005; 52:652-3.

2. Ozer S, Benumof JL. Oro-and nasogastric tube passage in intubated patients fiberoptic description of where they go at the laryngeal level and how to make them enter the esophagus. J Am Soc Anesthesiol 1999; 91:137-43.

3. Appukutty J, Shroff PP. Nasogastric tube insertion using different techniques in anesthetized patients: A prospective, randomized study. Anesth Analg 2009; 109:832-5.

4. Mandal MC, Dolai S, Ghosh S, Mistri PK, Roy R, Basu SR, et al. Comparison of four techniques of nasogastric tube insertion in anaesthetised, intubated patients: A randomized controlled trial. Indian J Anaesth 2014; 58:714.

5. Liua Y, Lowea AA, Zengb X, Fub M, Fleethamc JA. Cephalometric comparisons between Chinese and Caucasian patients with obstructive sleep apnea. Am J Orthod Dentofacial Orthop 2000; 117:479-85.

Sheema Siraj, Mehmood Mian and Fauzia Anis Khan

Department of Anaesthesiology, The Aga Khan University Hospital, Karachi.

Correspondence: Dr. Sheema Siraj, Resident, Department of Anaesthesiology, The Aga Khan University Hospital, Karachi. E-mail: sheema.siraj@aku.edu

Received: October 01, 2016; Accepted: December 20, 2016. 